\title{
Neonatal antiphospholipid syndrome
}

INSERM

\section{Source}

INSERM. (1999). Orphanet: an online rare disease and orphan drug data base. Neonatal antiphospholipid syndrome. ORPHA:398097

Neonatal antiphospholipid syndrome is a rare, secondary, neonatal autoimmune disease characterized by single or recurrent episodes of venous, arterial or mixed thrombosis in a neonate whose mother does not have antiphospholipid syndrome manifestations.

Patients present positive antiphospholipid antibodies and may have additional abnormalities associated (e.g. cardiac valve disease, livedo reticularis, thrombocytopenia, nephropathy, neurological manifestations). 